Article

\title{
A Typology of Attitudes towards the E-Bike against the Background of the Traditional Bicycle and the Car
}

\author{
Jadwiga Biegańska*(D), Elżbieta Grzelak-Kostulska (D) and Michał Adam Kwiatkowski \\ Department of Urban and Regional Development Studies, Faculty of Earth Sciences and Spatial Management, \\ Nicolaus Copernicus University in Toruń, Lwowska 1, 87-100 Toruń, Poland; grzelak@umk.pl (E.G.-K.); \\ kwiat@umk.pl (M.A.K.) \\ * Correspondence: jadwigab@umk.pl
}

Citation: Biegańska, J.;

Grzelak-Kostulska, E.; Kwiatkowski, M.A. A Typology of Attitudes towards the E-Bike against the Background of the Traditional Bicycle and the Car. Energies 2021, 14, 8430.

https://doi.org/10.3390/en14248430

Academic Editor: Marcin Połom

Received: 16 November 2021

Accepted: 11 December 2021

Published: 14 December 2021

Publisher's Note: MDPI stays neutral with regard to jurisdictional claims in published maps and institutional affiliations.

Copyright: (c) 2021 by the authors. Licensee MDPI, Basel, Switzerland. This article is an open access article distributed under the terms and conditions of the Creative Commons Attribution (CC BY) license (https:// creativecommons.org/licenses/by/ $4.0 /)$.

\begin{abstract}
Although it is generally accepted that innovators and early adopters have a particular influence on the uptake of electric bikes, other groups, whose reactions to innovation have not been studied, are perhaps wrongly marginalised. Such individuals, often relying on stereotypes, also need to be included in researchers' scope of interest. Therefore, the aim of the CAWI survey was to determine the attitudes of respondents, both users and non-users of electric bikes, and on this basis to classify by k-means analysis the attitudes towards the e-bike compared to the traditional bicycle and the car. The results obtained show a large variation between the designated classes. What most of them have in common is a strong attachment to the private car, which is typical for the cycling culture of this part of Europe, but the psycho-physical characteristics of the surveyed remain the strongest differentiating factor. Therefore, in the light of the opinions collected, it seems that the group Gadget lovers 1 and 2, whose share was about one-quarter of the total number surveyed, may be the most inclined to change their transport behaviour. This means that the e-bike, as an innovation, can overcome a critical discontinuity stage on the innovation diffusion curve in the Innovation Adaptation Lifecycle (IAL).
\end{abstract}

Keywords: e-bike; bicycle; cycling culture; cyclist typology; Poland

\section{Introduction}

In view of the increasing presence of electric bicycles on European roads, many questions arise about their impact on the future shape of mobility. The hopes attached to the beneficial effects of e-bikes seem justified, but it is worth basing them on rational premises and reinforcing them with effective actions built on well-informed strategies. Why, then, is it worth paying so much attention to e-bicycles? We can name several reasons. Firstly, as Bucher et al. [1] and Fishman and Cherry [2] show, electric bicycles are one of the most environmentally friendly means of transport. However, their role in the transition to low-carbon mobility is, according to Rérat [3], underestimated in debates on e-mobility, which tend to be monopolised by e-cars [4]. In addition, electric bicycles can play a special role in increasing the participation in cycling of those who have so far not used a bicycle at all [3,5]. A user group of particular interest in this context may comprise those who will benefit from increased travel range [6-10] or overcome their mobility limitations, which is particularly important for older people [7,11-13]. However, it is crucial here to make the public aware that contrary to some opinions [10], this type of transport brings not only environmental [14,15], but also health [16,17], benefits. These arguments could be very important as electric bikes have a real chance to replace car travel, as has already been documented in research $[18,19]$. This is particularly relevant in countries with an underdeveloped cycling culture [20] and a low level of cycling policy, such as Poland [21].

E-bike use depends on many factors such as wealth, age, health status [3,8], the propensity to reach for innovative solutions [22-27], opportunity understood as free access, resulting from the possibility of using one's own or borrowed bicycle, environmental 
conditions (such as the climate of a given place), terrain [28], the presence of cycling infrastructure (from cycle routes through service stations to safe parking places), and similar features broadly understood as socio-economic and environmental conditions and urban morphology [29-31]. These factors operate at different intensities depending on the area or the respondents themselves [32-34]. The results of the research tackling the influence that different determinants exert on the perception of e-bikes are certainly very practical, especially at the micro-scale, for making specific spatial decisions. However, the aim of the conducted research was not to search for e-bike users or to establish influence on them, but to make a general diagnosis on the attitudes towards e-biking in Poland. The groups of respondents classified on this basis were analysed in terms of their susceptibility to adopt innovations, which is key to the e-bike research. This approach is related to the adopted theoretical perspective set by the Innovation Adaptation Lifecycle (IAL).

The framework of this concept locates the e-bike as an innovation that is in the initial phase of the product life cycle. The results of the survey showed that the percentage of respondents who used this product did not exceed $8 \%$ of the total number of respondents. Thus, this group can, according to the widely accepted concept of Moore [35], be categorised as innovators and early adopters.

As many researchers have pointed out, the success of innovation is very much determined by the knowledge regarding users because, as [36] rightly pointed out, the diffusion of consumer products is a social process, as already described by Everett Rogers in his classic 1962 work "Diffusions of innovations" [37]. He also paid special attention to innovators and early adopters [37] because, in his opinion, through them, it is possible to change the existing cultural and semantic context surrounding a new product or technology. Many other publications have also paid attention to the category of early adopters $[22-27,38,39]$. In the context of e-bikes, Seebauer [23] wrote about early adopters, noting the heterogeneity of actors in the diffusion process: those who are opinion leaders and those who display varying degrees of susceptibility to innovation. In his research, he devoted attention to the first group, but opened up the field for broader research with his insights. From this perspective, the authors see a research gap in the lack of research taking into account not only the category of innovators and early adopters, but also others, i.e., potential users. Learning about them provides an opportunity to understand the background of the stereotypes constructed, which may be responsible for facilitating or hindering the diffusion of innovation. A deeply manifested dislike of certain solutions can affect the opinions of others, especially since the perception of the e-bike in the study area is determined by stereotypes for more than $90 \%$ of the respondents. They are guided by such thought patterns because they do not have their own experience in using e-bikes. Thus, functioning perceptions based on unverified information become key elements in determining people's opinions. Their shape may vary as it depends on the individual characteristics of respondents, but on a general scale, it is influenced by the broader spatial context [34,40-43].

The authors, therefore, considered two elements to be the experience determining the attitudes towards the e-bike in Poland: (1) previous contact with and use of the e-bike, and (2) the impact of the place of residence, understood in terms of the influence of cycling culture-differing between countries with different socio-economic situations, mobility traditions, etc.

The adopted perspective imposes the shape of the conducted narration as to its content, which is also reflected in the formal arrangement of the paper. It starts with the description of a broader background to the problem under study outlined in the section reviewing relevant perspectives reported in the current literature. Further on, it describes necessary explanations of the analytical methods used to classify the attitudes of the respondents into users and non-users of electric bikes. The results collected open the field for discussion. It refers to the conceptual framework set by the IAL as well as to the findings reported in the literature, which take into account, among other things, the geographical context. The deliberations end with conclusions with a suggestion for the implementation of the results obtained. 


\section{Literature Background}

Although the main problem posed here is laying the groundwork for the successful implementation of the innovation that the e-bike represents, as Rérat [3] rightly notes, the growing popularity of the e-bike, its cohabitation with the mechanical bicycle, and its replacement of the car are key elements in the transition to low-carbon mobility. Research is also certainly needed on the similarities and differences between e-bikes and conventional cycling in relation to the perceived role of the private car. All the more so as there has been little research on this issue to date, particularly in central and eastern Europe, and the cultural context seems particularly important here.

Cycling culture in Poland comes down to perceiving the bicycle mainly as a tool of recreation. The preferred means of transport is the passenger car (the passenger car was a marker of higher social status for years, and the difficulty of acquiring one until the 1990s caused by low supply on the market placed it in the category of particularly desirable luxury goods). However, the way the bicycle is used varies due to different perceptions of the bicycle in western Europe [3], North America [44], and China [45], where the popularity of e-bikes has increased significantly in recent years [46-48]. The results of studies carried out so far confirm that cycling culture in the world is diverse, which confirms the relevance of the geographical aspect adopted in our study. The transport function of the bicycle is much more often realised in rural areas, where it was often perceived as a necessity in view of the need to cover longer distances in the absence or significantly reduced range of public transport and the lack of a car. At present, the significant popularisation and availability of cheap second-hand cars have largely reduced the need for cycling (except for selected social groups, such as elderly women). The car is not regarded as an indicator of social status to such an extent as before, but the convenience it provides is still desired. The bicycle, in this view, is rated much lower (it provides less comfort), and therefore it is assigned a different role. In this context, on the one hand, it can be regarded as a certain symbol:

"As an efficient means of locomotion, it is still more frequently used in the countryside than in the city, but it is among the bustling streets, intersections, and pavements that it gains a special status and becomes a sign of choice of a certain lifestyle that belongs to the urban aesthetics and culture." [49]

The bicycle is also assigned a recreational function, increasingly popular in the face of the promotion of healthy lifestyles. However, this has some serious implications for the perception of e-bikes. As shown in publications, e-biking can be beneficial for health and fitness, providing a way for couples to exercise and cycle together (bridging differences resulting from different physical conditions) [50], and can also supply moderate-intensity physical activity [16]. Nevertheless, e-bikes are rated very low in this scope, and their certain features may be perceived negatively. As pointed out by some researchers $[4,6,50,51]$, the e-bike carries a kind of social stigma, being associated with the elderly or with the idea that using electric assistance is 'cheating' rather than 'proper cycling', which discourages many traditional bicycle users from reaching for the electric equivalent over longer distances. The evaluation of e-bike use is further complicated by its perception as an innovative or technophilic mode of transport [24], which, on the one hand, may help to overcome the social pressure of the car, but on the other hand may be interpreted as a manifestation of a fad not worth paying attention to. The multitude of attitudes and opinions concerning the use of e-bikes confirms the need, also indicated by other researchers, to organise the knowledge on the topic. In the development of the e-cycling form of mobility, a very important but often overlooked issue is the adaptation of cycling infrastructure to both traditional and electrically assisted bicycles. In the context of the needs and capabilities of e-bikes, it is particularly important to create a network of cycleways convenient for covering longer distances at higher speeds and avoiding collisions and interactions with other road users [52]. Joining in the scientific discussion on how to successfully transition to low-carbon mobility, we, like many other researchers, believe that one of the measures could be the replacement of the private car by bicycle transport. It is therefore desirable 
that traditional bicycles continue to disseminate, but electric bicycles can play a greater role, especially in the realisation of the transport function. We consider it more competitive with the car as it allows you to cover more distance with little effort. We, therefore, want to know what role is attributed to electric bicycles and what constraints on the use of this mode of transport are indicated by both those who have had contact with it and those who have not. Going further, we would like to examine how the opinions of the surveyed vary, whether it is possible to identify certain groups among them, what priorities in mobility behaviour these groups are guided by, and what is their judgement regarding e-bikes. Finally, we aim to verify whether the experience of using e-bikes is the only factor that influences the respondents' opinions, or whether there are other elements, such as cycling culture, geographical specifics, or individual characteristics. This will allow us to provide guidelines for preparing an information campaign, e.g., as to who should be its target audience in the first place (as it would give a better chance to change the recipients' habits). Such measures will ultimately make it possible to determine what the real chances are of effectively reducing car traffic.

\section{Research Methods}

The problem tackled in this article determined the methods used by the authors. A survey technique was used in order to investigate the perception of the electric bicycle in comparison with the traditional bicycle and the passenger car. It took the form of a computer-assisted web interview (CAWI). This technique allows the researcher to generate an electronic version of the survey and the respondent to take part in the study at their convenience by clicking on a link. Moreover, CAWI also offers additional possibilities, such as the use of an extended range of functionalities, precise instructions, greater clarity of questions, or finally, greater flexibility in the conduct of the survey itself [53-55]. As a result, already in the mid-2010s, more than one-third of all social surveys in Poland were conducted using this technique [56].

In the case of this original nationwide social survey, the questionnaire was designed, and then the survey itself was conducted using the LimeSurvey online platform. An important rationale for abandoning the traditional PAPI (pencil and paper interview) survey technique was the pandemic context. The survey itself was conducted in May 2021. Thus, for the safety of both researchers and respondents, face-to-face contact was abandoned. The prepared questionnaire in electronic form was placed in the form of a link on local government websites. The survey mainly comprised of closed questions, which allowed for greater standardisation of the data and comparability of the results obtained. It was conducted in May 2021 and included 456 respondents. The selection of the sample was non-random and dictated largely by its availability (cf. [57]). However, it was assumed that such a sample size was sufficient for careful inference and generalisation of the results obtained. The raw data collected were coded and validated in the PS Imago 27 program, which also served to prepare statistical comparisons. An important limitation of the study was the low percentage of people who used electric bikes. However, the sample attempted to reflect the distribution of the variable in the population. Nevertheless, obtaining a higher number of indications from respondents using electric bikes would allow for a wider analysis of their perception and perceived benefits, which could have a significant impact on recommendations related to encouraging people who have never used this form of transport.

The study sample was predominantly female at $65.1 \%$, while the remaining $34.9 \%$ were men. The survey itself was designed to include people with different demographic and social characteristics. Thus, for example, the age range of respondents was 18 to 72 years. Taking into account the size of the settlement unit, 55.9\% of respondents declared that they came from a big city with over 100,000 inhabitants, 15.1\% from a medium-sized city (20,000-100,000 inhabitants), $11.8 \%$ from a small town ( $<20,000$ inhabitants), $2 \%$ from a suburban area, and $15.1 \%$ from a village. The majority of respondents described their material situation as good $(59.2 \%)$ or average $(28.9 \%)$. Key to the study, however, was 
to find people who used an electric bike. Their share in the total sample was $7.9 \%$. The opinions of e-bike users were contrasted in the empirical part with the opinions of people who had never used this means of transport.

The adopted axis of division of the respondents was reflected in the proposed classification of attitudes and social behaviour concerning the electric bicycle against the traditional bicycle and the car. Statistica 13 was employed for classification purposes. In this context, two separate classifications were constructed, one including only respondents who had used an electric bicycle, the other including respondents who had not yet had contact with one. The k-means method was used to prepare both classifications on the assumption that individual characteristics are insufficient to infer relationships between variables. Furthermore, they may be subject to error due to the randomness of the data collected. The k-means method belongs to a group of methods in multivariate statistics in which homogeneous subsets of objects are extracted from the studied whole [58]. Importantly, the procedure of separating similar subsets-clusters-is not a simple statistical test. Rather, it is a collection of different algorithms that allow objects to be grouped into clusters. In k-means analysis, two objects are assumed to be more similar, the smaller the distance between them. The transition from a similarity function to a distance function and vice versa is implemented by simple mathematical transformations. As a result, we combine two objects into a single cluster if they lie close to each other yet far from other clusters $[59,60]$.

The k-means analysis yielded two classifications. The first one, as mentioned, included only people who had ridden an electric bicycle before. Two clusters were distinguished here, reflecting similar attitudes and behaviours. The second classification, which includes people not previously using an electric bicycle, was divided into three clusters. Grouping with the k-means method is an iterative procedure (cf. [61]). In each subsequent iteration, objects are moved to other clusters in order to achieve the correct solution in which objects are classified in the correct groups. In the data matrix introduced in the analysis, the solution for the first classification was found in the third iteration, while two iterations were necessary for the second classification. The k-means procedure using Euclidean distance was carried out according to the formula:

$$
d_{i j}=\frac{N_{p}}{N_{j}} d_{i p}+\frac{N_{q}}{N_{j}} d_{i q}
$$

where:

$$
d(x, y)=\sqrt{\sum_{i+1}^{p}\left(x_{1}-y_{i}\right)^{2}}
$$

where $\mathrm{x}=\left(\mathrm{x}_{1}, \ldots, \mathrm{x}_{\mathrm{p}}\right)$ :

$$
\mathrm{y}=\left(\mathrm{y}_{1}, \ldots \mathrm{y}_{\mathrm{p}}\right), \mathrm{p}=1,2,3, \ldots, \mathrm{n}
$$

In both cases, 44 variables were considered, as some of the key questions for the study offered multiple choice. The list of questions and variables are listed in the Table 1.

All questions were standardised according to the following formula:

$$
\mathrm{z}_{\mathrm{i}}=\frac{\mathrm{x}_{\mathrm{i}}-\mathrm{x}}{\mathrm{s}_{\mathrm{x}}}
$$

where:

$\bar{x}$-arithmetic mean

$s$-standard deviation. 
Table 1. List of questions and variables employed in the study.

\begin{tabular}{|c|c|c|}
\hline No. & Basic Question & Variables (Options of the Basic Question) \\
\hline 1. & $\begin{array}{c}\text { What do you think a traditional } \\
\text { bicycle and an electric bicycle } \\
\text { are used for? }\end{array}$ & $\begin{array}{l}\mathrm{x}_{1} \text {-What do you think a traditional bicycle and an electric bicycle are used for? } \\
\text { (1-least, } 5 \text { - most). Means of transport. Traditional bicycle; } \\
\mathrm{x}_{2} \text {-What do you think a traditional bicycle and an electric bicycle are used for? } \\
\text { (1-least, } 5 \text { - most). Means of transport. Electric bicycle; } \\
\mathrm{x}_{3} \text {-What do you think a traditional bicycle and an electric bicycle are used for? } \\
\text { (1-least, } 5 \text { - most). Recreation. Traditional bicycle; } \\
\mathrm{x}_{4} \text {-What do you think a traditional bicycle and an electric bicycle are used for? } \\
\text { (1-least, } 5 \text { - most). Recreation. Electric bicycle; } \\
\mathrm{x}_{5} \text {-What do you think a traditional bicycle and an electric bicycle are used for? } \\
(1 \text {-least, } 5 \text { - most). Health and fitness. Traditional bicycle; } \\
\mathrm{x}_{6} \text {-What do you think a traditional bicycle and an electric bicycle are used for? } \\
(1-\text { least, } 5 \text { - most). Health and fitness. Electric bicycle; }\end{array}$ \\
\hline 2. & $\begin{array}{l}\text { Assuming you have access to } \\
\text { both a traditional bicycle and an } \\
\text { e-bike, please indicate which } \\
\text { one you would use in each } \\
\text { situation? }\end{array}$ & 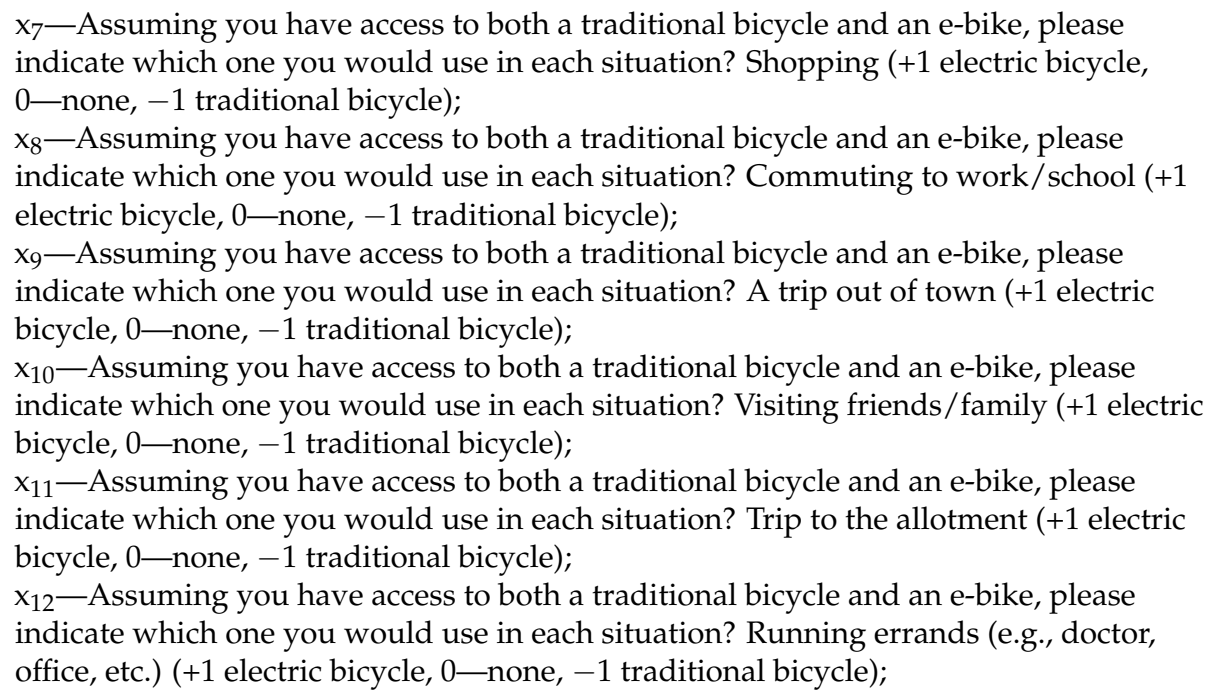 \\
\hline 3. & $\begin{array}{l}\text { Please rate the following means } \\
\text { of transport in the aspects } \\
\text { indicated (1-not suitable, } \\
\text { 5-best suitable). }\end{array}$ & 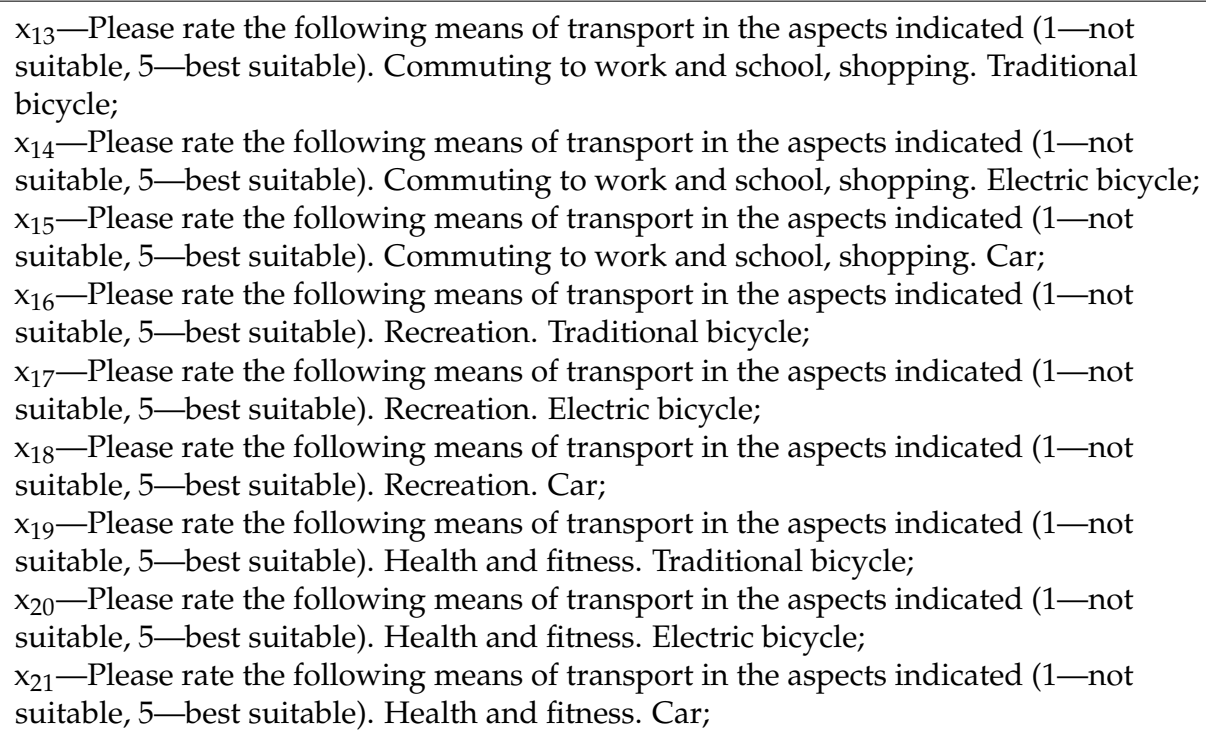 \\
\hline
\end{tabular}


Table 1. Cont.

\begin{tabular}{cc}
\hline No. & Basic Question \\
\hline & \\
& Which of the options listed \\
below best fits the \\
characteristics indicated?
\end{tabular}
$\mathrm{x}_{22}$-Which of the options listed below best fits the characteristics indicated: it is suitable for everyone ( 1 -yes, 0 - no);
$\mathrm{x}_{23}$-Which of the options listed below best fits the characteristics indicated: it is especially useful for the elderly ( 1 -yes, 0 -no);
$\mathrm{x}_{24}$-Which of the options listed below best fits the characteristics indicated: it can travel long distances (1-yes, 0 -no);
$\mathrm{x}_{25}$-Which of the options listed below best fits the characteristics indicated: it is useful when the terrain is not flat (1-yes, 0 -no);
$\mathrm{x}_{26}$-Which of the options listed below best fits the characteristics indicated: it is trendy (1-yes, 0-no);
$\mathrm{x}_{27}$-Which of the options listed below best fits the characteristics indicated: it gives more pleasure from riding it ( 1 -yes, 0 -no);
$\mathrm{x}_{28}$-Which of the options listed below best fits the characteristics indicated: it is safer (1-yes, 0 -no);
$\mathrm{x}_{29}-$ Which of the options listed below best fits the characteristics indicated: it is expensive (1-yes, 0 -no);
$\mathrm{x}_{30}$-Which of the options listed below best fits the characteristics indicated: it is more suitable for everyday use (1-yes, 0 -no);
$\mathrm{x}_{31}$-Which of the options listed below best fits the characteristics indicated: it is more practical (1-yes, 0-no);
$\mathrm{x}_{32}$-Which of the options listed below best fits the characteristics indicated: for villagers (1-yes, 0 -no);
$\mathrm{x}_{33}$-Which of the options listed below best fits the characteristics indicated: for city dwellers (1-yes, 0 -no);
$\mathrm{x}_{34}$-Which of the options listed below best fits the characteristics indicated: it is ecological (1-yes, 0 -no);
$\mathrm{x}_{35}$-Which of the options listed below best fits the characteristics indicated: I would prefer to have (1-yes, 0 -no);

$\mathrm{x}_{36}$-Please tick the statements with which you agree: the fashion for electric bikes is temporary and will soon pass ( 1 -yes, 0 -no);

$\mathrm{x}_{37}$-Please tick the statements with which you agree: I tend to use my car a lot, even for short distances (1-yes, 0 -no);

$\mathrm{x}_{38}$-Please tick the statements with which you agree: electric bikes should be available in bike hire schemes (1-yes, 0 -no);

$\mathrm{x}_{39}$-Please tick the statements with which you agree: a bike is good for a trip, but a car is better for everyday life (1-yes, $0-$ no);

5. Please tick the statements with which you agree.
$\mathrm{x}_{40}$-Please tick the statements with which you agree: I would be happy to reduce my car use and replace it with a traditional bike (1-yes, 0 -no);

$\mathrm{x}_{41}$-Please tick the statements with which you agree: I would be happy to reduce my car use and replace it with an electric bike (1-yes, 0 - no);

$\mathrm{x}_{42}$-Please tick the statements with which you agree: A car is an indicator of higher material status ( 1 -yes, 0 -no);

$\mathrm{x}_{43}$-Please tick the statements with which you agree: the electric bicycle is an indicator of higher material status (1-yes, $0-$ no);

$\mathrm{x}_{44}$-Please tick the statements with which you agree: the electric bike is better than the traditional bike (1-yes, 0 -no).

Data were standardised to eliminate the influence of the different measurement scales by which they were collated. This procedure also allowed for a better comparison of the variables, which was not without influence on the final result of the classification $[62,63]$ (cf. Figure 1). 


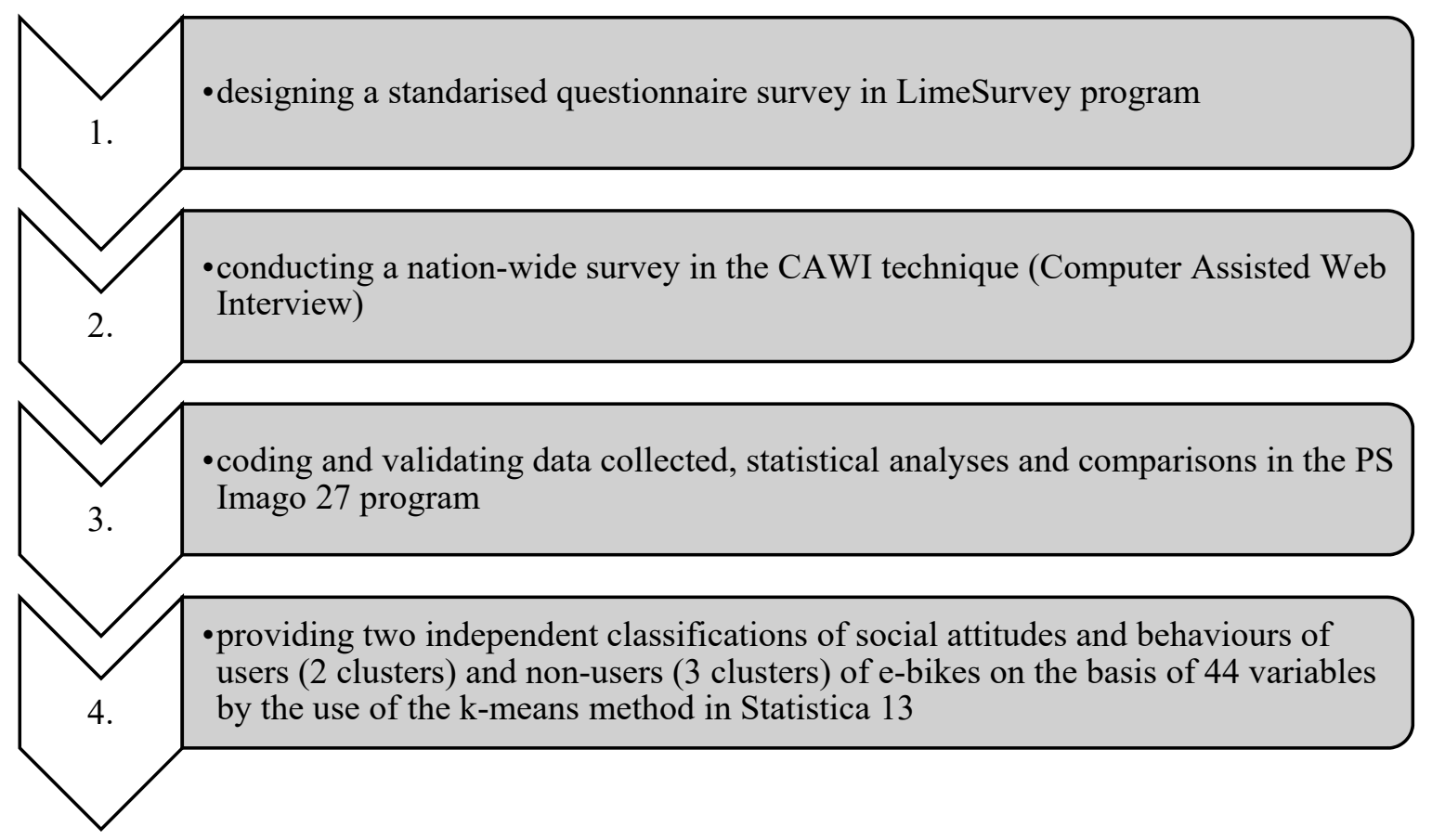

Figure 1. Outline of the research methodology. Source: own elaboration.

\section{Research Results: Classification of Attitudes and Behaviours among Users and Non-Users of Electric Bicycles}

Two classifications of attitudes and behaviours towards the e-bike versus the traditional bicycle and the car are proposed to present the obtained results and to indicate regularities (see Figure 2).

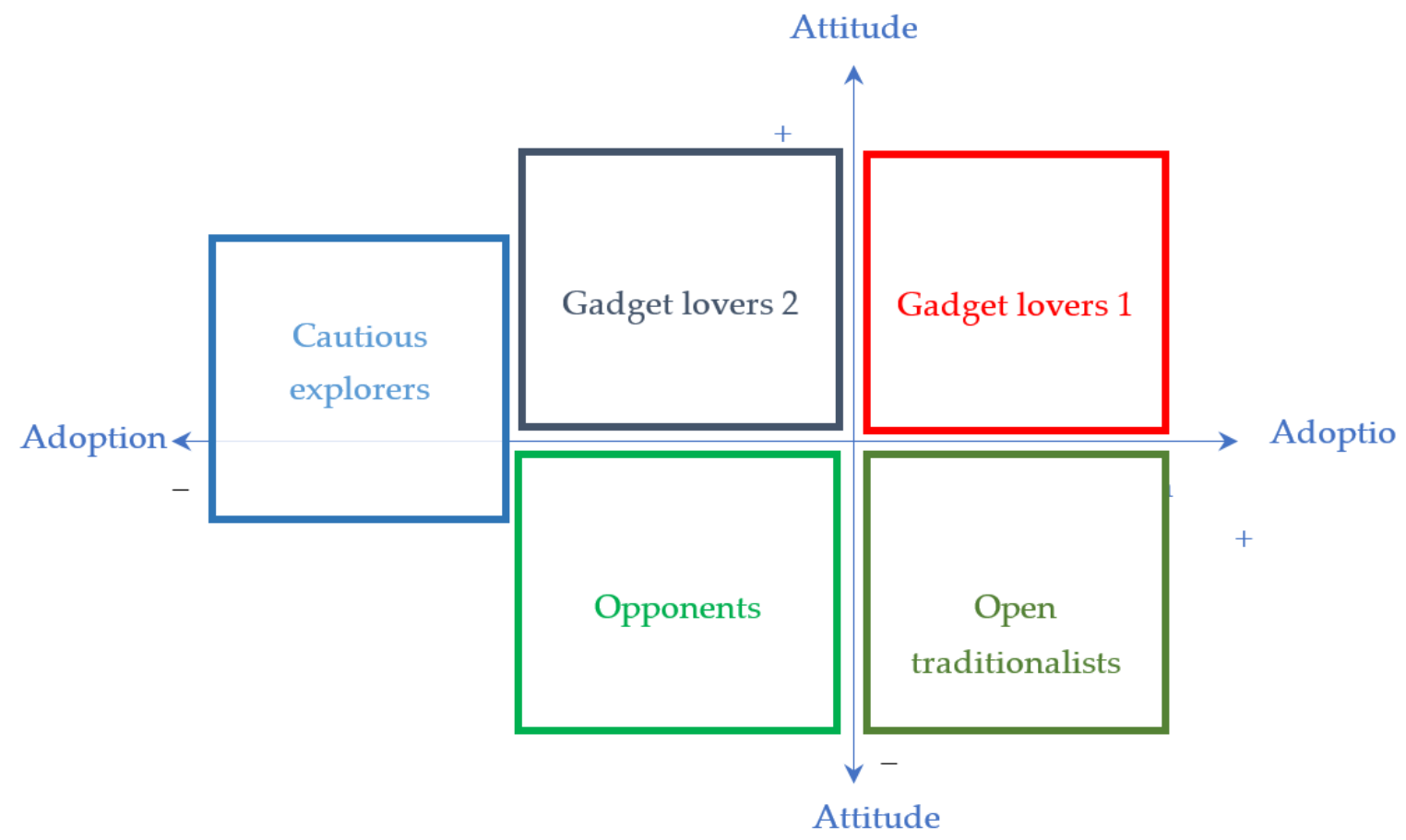

Figure 2. Types of e-bike users and non-users. Source: own elaboration on the basis of the questionnaire survey. 


\subsection{Users of Electric Bicycles}

The first classification only included people who had used electric bikes before (Figure 3). Within this group, two clusters (subgroups) reflecting different attitudes and behaviours were identified. They were equal in size and included 3.9\% of the respondents each. In terms of socio-demographic characteristics, this group was relatively young $(\mu=-0.68)$, had a good opinion of their material situation $(\mu=0.45)$, and declared a high level of education (the vast majority were people with university and secondary education). Moreover, almost $60 \%$ of all respondents were male, mainly from urban areas $(\mu=0.19)$.

Gadget lovers 1 . The first cluster was represented by respondents who were strong supporters of the electric bike for recreational purposes $(\mu=0.64)$, moderate supporters for health and fitness $(\mu=0.37)$, and minimal supporters of the electric bike as a means of transport $(\mu=0.10$. Assuming equal access to electric and traditional bikes, respondents assigned to this cluster preferred to use electric bikes in particular when visiting family and friends $(\mu=0.71)$, going for a trip out of town $(\mu=0.44)$, or going to the allotment $(\mu=0.37)$. Interestingly, if they had equal access to both bikes, they would also choose to use the electric bike to commute to work $(\mu=0.60)$, and slightly less often to go shopping $(\mu=0.30)$, or to run errands such as the doctor's or an office $(\mu=0.12)$. However, it is worth noting that they rated the car highest as a means of transport $(\mu=0.44)$ and the electric bicycle for recreation and health and fitness purposes ( $\mu=0.41$ and $\mu=0.27$, respectively). They concurred that the electric bike was expensive $(\mu=1.0)$, but at the same time trendy $(\mu=0.70)$, more fun to ride $(\mu=0.66)$, and they would therefore prefer to own one $(\mu=0.70)$. They saw electric bikes as dedicated to both urban $(\mu=0.57)$ and rural dwellers $(\mu=0.50)$, probably because in their opinion they were more practical $(\mu=0.50)$, suitable for everyday use $(\mu=0.50)$, and could cover long distances $(\mu=0.44)$ and reliefs $(\mu=0.44)$. They also believed that e-bikes were more environmentally friendly than traditional bikes $(\mu=0.30)$, but not particularly suitable for the elderly $(\mu=-0.44)$. In general, this group saw the e-bike as a kind of gadget, emphasising that the fashion for e-bikes was temporary and would soon pass $(\mu=0.70)$; however, they deemed the e-bike an important marker of material status $(\mu=0.57)$, and therefore they strongly preferred it to a traditional bike $(\mu=0.57)$. That said, they tended to use a car on a daily basis, even for short distances $(\mu=0.44)$.

Open traditionalists. In contrast to the first group of e-bike users characterised above, the second group rated the traditional bicycle as most important for recreation and health and fitness purposes ( $\mu=0.65$ and $\mu=1.00$, respectively), and the e-bike as having some importance for transport purposes $(\mu=0.17)$. Assuming equal access to both bikes, they would choose the traditional bicycle to go to work and school $(\mu=-0.72)$, but also for recreational purposes (including a trip out of town $(\mu=-0.80)$, visiting friends and family $(\mu=-0.85)$, or going to the allotment $(\mu=-0.62))$. In general, they rated both bikes very high for transport purposes (traditional bike 0.54 and electric bike $\mu=0.41$ ), while rating the car low $(\mu=-0.62)$. The traditional bicycle was the only mode of transport that received very high or high ratings for recreational and health and fitness purposes ( $\mu=0.53$ and $\mu=0.30$, respectively). The cluster considered electric bikes to be expensive $(\mu=1.00)$ and recommended primarily for older people $(\mu=0.44)$. On the other hand, the traditional bicycle was seen as giving more riding pleasure $(\mu=-0.99)$, trendy $(\mu=-0.98)$, better for everyday use $(\mu=-0.83)$, especially for city-dwellers $(\mu=-0.80)$, practical for longer distances $(\mu=-0.62)$, and therefore this group preferred it over the electric bicycle $(\mu=-0.98)$. What was particularly surprising was that they did not think that the fashion for e-bikes was temporary $(\mu=-0.98)$, nor perceive e-bikes as an indicator of higher material status $(\mu=-0.57)$. They quite rarely used the car for short distances $(\mu=-0.44)$. This group, on the basis of their attitudes and declared behaviour, treated the electric bicycle as one of the possible means of transport, especially in the city, at the same time trying to reduce the use of the car as much as possible by utilising the traditional bicycle and treating it as a lifestyle and conscious choice. 


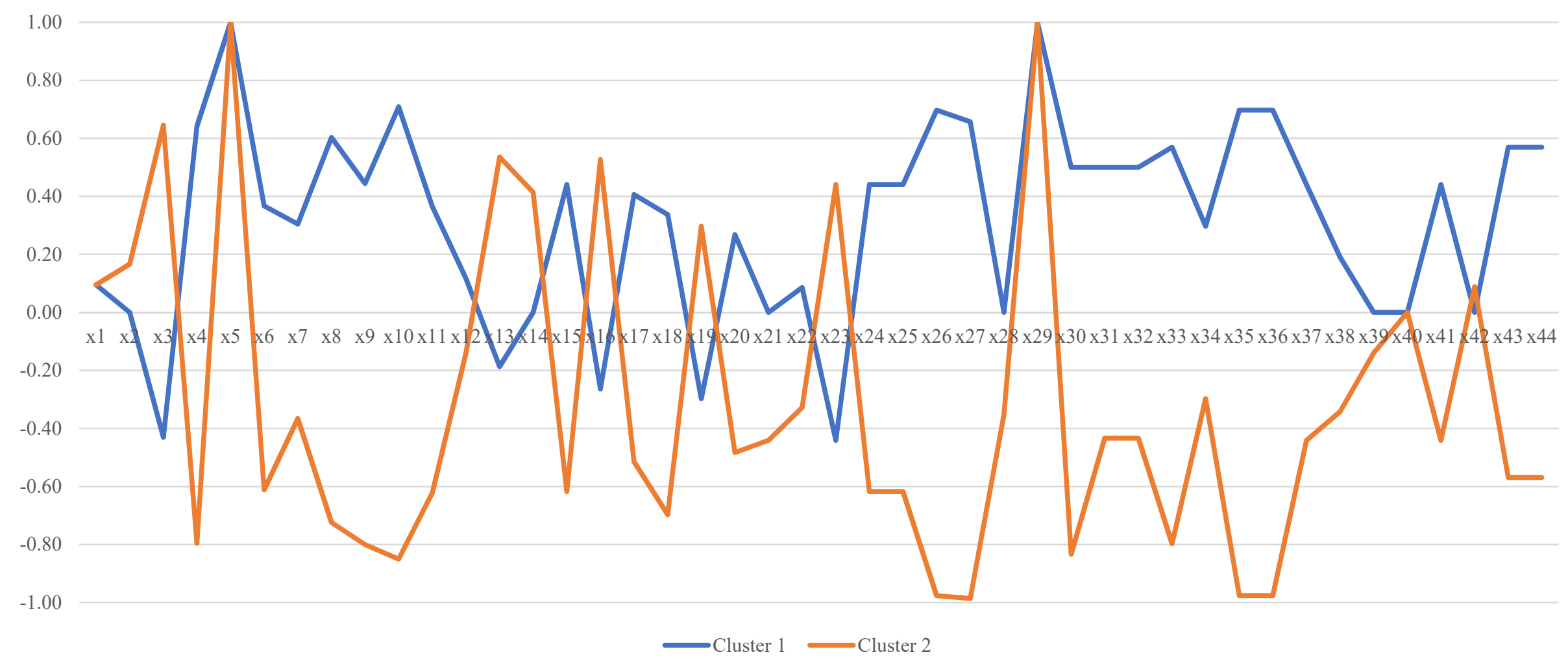

Figure 3. Mean values of clusters for the classification of users of electric bicycles. Explanation as in Table 1. Source: own elaboration on the basis of the questionnaire survey. 


\subsection{Non-Users of Electric Bicycles}

The second classification analysed the declarations of people who had never used an electric bike before (Figure 4). This group stood out among respondents by the high proportion of women (almost 2/3). Moreover, the respondents classified here declared a lower-than-average level of education (a lower percentage of respondents with secondary and higher education and a higher percentage with basic vocational and primary education) and income $(\mu=-0.33)$. In contrast to the group of people who had previously used e-bikes, they were also older $(\mu=0.41)$ and had a wider age range. They were slightly more likely than e-bike users to declare a rural origin $(\mu=-0.23)$. Three clusters (subgroups) were identified here.

Opponents. The representatives of the first group, who accounted for $42.1 \%$ of all respondents, were strong opponents of electric bikes, despite the fact that they had never used one. When comparing the preferences of this group regarding traditional and electric bikes, they ranked electric bikes low as a means of transport $(\mu=-0.28)$, and very low as a tool for recreation $(\mu=-0.70)$, and health and fitness $(\mu=-0.59)$. Assuming equal access to both types of bicycles, they would opt for the traditional bicycle both for trips to work, school $(\mu=-0.13)$, for shopping $(\mu=-0.33)$, for errands such as doctors, offices ( $\mu=-0.31)$, or for recreational trips to the allotment $(\mu=-0.39)$, to visit friends $(\mu=-0.26)$, or for trips out of town $(\mu=-0.26)$. When evaluating modes of transport, they consistently rated the electric bicycle very negatively, while assessing the traditional bicycle and the car positively, but the latter only as a means of transport $(\mu=0.26)$. They agreed that the traditional bike had more advantages, as it was better for everyday use $(\mu=-0.30)$, suitable for everyone $(\mu=-0.25)$ : both the urban $(\mu=-0.33)$ and rural population $(\mu=-0.24)$, safer $(\mu=-0.27)$, and above all, trendy $(\mu=-0.39)$. If they were to reduce their use of the car, it would only be by replacing it with the traditional bicycle $(\mu=0.11)$, because in their opinion, the electric bicycle was not an indicator of higher material status $(\mu=-0.29)$, and the fashion for the bicycle was temporary and would soon pass $(\mu=0.17)$.

Cautious explorers. The second group included respondents (28.3\%) who showed a strong interest in electric bikes, but only in a recreational $(\mu=0.81)$ and health and fitness context $(\mu=0.97)$. Assuming equal access to an electric and a traditional bicycle, they would opt for an electric bicycle when riding for recreational purposes to the allotment $(\mu=0.43)$ or for a trip out of town $(\mu=0.31)$. For work, school $(\mu=-0.25)$, shopping $(\mu=-0.15)$, and errands such as the doctor or the office $(\mu=-0.22)$, they would rather use a traditional bike. When rating transport modes, they ranked the electric bicycle very high in the recreational $(\mu=0.83)$ and health and fitness $(\mu=0.90)$ contexts, while in the transport context, they tended to prefer the traditional bicycle $(\mu=0.26)$, and very rarely the $\operatorname{car}(\mu=-0.33)$. Interestingly, they assessed the car quite positively as a tool for recreation $(\mu=0.28)$ and health and fitness $(\mu=0.29)$. This group is quite poorly profiled regarding identification with both traditional and electric bikes. Nevertheless, when it comes to indicating which bike is suitable for everyone $(\mu=-0.34)$, for everyday use $(\mu=-0.27)$, and is more practical $(\mu=-0.25)$, they were inclined to point to the traditional one. For them, the electric bicycle was an indicator of higher material status $(\mu=0.23)$, but they would rather reduce their use of the car as a means of transport by replacing it with a traditional bicycle $(\mu=0.24)$. 


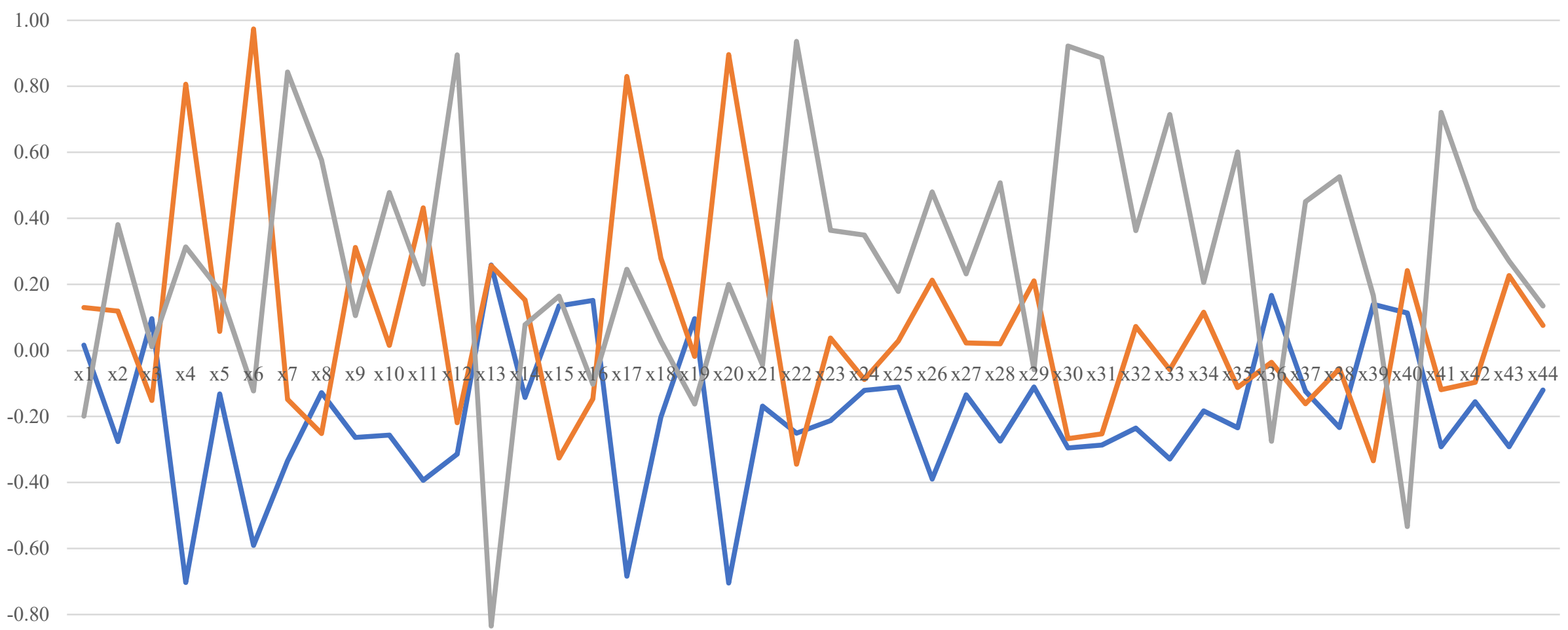

$-1.00$

$\longrightarrow$ Cluster $1 \longrightarrow$ Cluster $2 \longrightarrow$ Cluster 3

Figure 4. Mean values of clusters for the classification of users of electric bicycles. Explanation: as in Table 1. Source: own elaboration on the basis of the questionnaire survey. 
Gadget lovers 2. The third group (21.7\% of all respondents) expressed interest in the electric bicycle as a means of transport $(\mu=0.38)$ and partly as a recreational tool $(\mu=0.31)$. Assuming equal access to both types of bicycles, they would certainly choose an e-bike for running errands such as the office or the doctor $(\mu=0.89)$, shopping $(\mu=0.84)$, commuting to work or school $(\mu=0.58)$, and even for visiting friends and family $(\mu=0.48)$, or slightly less frequently for going to the allotment $(\mu=0.20)$, or for a trip out of town $(\mu=0.11)$. At the same time, they rated the traditional bicycle very low as a means of transport $(\mu=-0.83)$, with the car rated highest in this respect $(\mu=0.16)$. However, they recognised a number of advantages of the electric bike, including the fact that it was suitable for everyone $(\mu=0.94)$, for everyday use $(\mu=0.92)$, more practical $(\mu=0.89)$, especially for city-dwellers $(\mu=0.71)$, and also safer $(\mu=0.51)$, and therefore trendy $(\mu=0.48)$, so they would prefer it greatly to the traditional bike $(\mu=0.60)$. This cluster tended to use the car even for short distances $(\mu=0.45)$. In addition, they considered the car $(\mu=0.43)$, but also partly the electric bicycle $(\mu=0.27)$, to be indicators of higher material status. Therefore, if they were to reduce car use, it would only be in favour of e-bikes $(\mu=0.72)$. They also postulated that electric bikes should be available in rental schemes $(\mu=0.53)$.

\section{Discussion}

The early identification of innovators and early adopters is considered fundamental when developing marketing strategies [64]. This is certainly a legitimate approach towards choosing routes to market expansion, especially with an awareness of the risk described by Moore in his work 'Crossing the chasm' [35] as a discontinuity in the diffusion of the innovation curve. The e-bike in Poland considered from the perspective of the IAL is, according to our research, approaching the biggest discontinuity, according to Moore [35]. A well-chosen strategy for bridging the gap in attracting innovation recipients from the successive groups of the early and late majority seems to be crucial for the success of the implementation of eco-mobile solutions, in this case, related to e-bikes.

The present study indicates that it may be important to identify not only the attitudes and behaviours of those using the innovation but also those who may benefit from it in the future. Their varying degrees of susceptibility to the new product open up a very interesting area for discussion on the need to monitor the opinions of this section of the public as well. Their views, as we know, are based on stereotypes that show variability over time [65]. That is why it is so important to know the different motives that shape them, and in particular, the motives of the group of determined opponents, especially as it represents as much as $42.1 \%$ of the total number of respondents.

Moreover, the survey revealed that the respondents were quite unfamiliar with electric bicycles, which partly underpinned the negative perception of electric bikes. The need to promote electric bicycles as a means of transport that is particularly beneficial to cities and their inhabitants was therefore once again demonstrated. This is a demand that has also appeared in earlier publications $[10,24,25,66,67]$. However, the results obtained from this study allowed us to outline the differences between the opinions about electric bicycles in different groups of respondents. In effect, it was possible to delineate two groups comprising a total of five subgroups of respondents characterised by different attitudes towards electric bikes. This aimed to describe types of people with different characteristics and attitudes towards this mode of transport. At this stage, this yielded a better understanding of the stated attitudes, and in subsequent stages, it will help better target measures related to raising awareness of the benefits of this mode of transport. Furthermore, as pointed out by Felix et al. [68], the breakdown by group allowed for better identification of the needs of individual respondents, which is not negligible in the context of promoting this solution. Previous studies have also shown that differences in perceptions of cycling, in general, may be rooted both geographically (due to cycling culture) [69] and in the psycho-physical characteristics of respondents [70].

No typology related to e-bikes has been developed in the published works so far, either in a narrower dimension, i.e., the group of e-bike users, or in a broader dimension of 
the whole population. The literature has introduced typologies of cyclists into the scientific discussion, based on different contexts and characteristics of the people studied. One of the most widely discussed is the classification of Geller [71], also analysed in the works of Dill and McNeal [72], Dill and McNeal [73], and Cabral and Kim [74], referring to attitudes towards cycling among Portland respondents. Another typology was proposed by DamantSirois et al., 2014 [75], referring to cyclists' attitudes in the context of cycling conditions. In turn, Francke et al. [76] applied their typology to the safety levels of infrastructure. There are also typologies relating to bicycle-sharing system use [77] as well as bicycle use in multimodal transport [78]. As part of our study, we verified the similarities between our delineated respondent types and three typologies frequently cited in the literature- those of Geller [71], Damant-Sirois et al. [75], and Francke et al. [76]. In putting together the characteristics of the different groups, we kept in mind that only to a certain extent can they correspond to the typologies set out in earlier studies (cf. Table 2).

Table 2. Proposed typology against the background of other classifications.

\begin{tabular}{|c|c|c|c|c|c|}
\hline \multirow{2}{*}{\multicolumn{2}{|c|}{$\begin{array}{l}\text { Typology Proposed in the } \\
\text { Research }\end{array}$}} & Author(s) & Geller [71] & Damant-Sirois et al. [75] & Francke et al. [76] \\
\hline & & Year & 2006 & 2014 & 2019 \\
\hline \multirow{2}{*}{ USERS } & \multicolumn{2}{|c|}{ Gadget lovers } & $\begin{array}{l}\text { Strong and the Fearless, } \\
\text { Enthused and Confident }\end{array}$ & Dedicated cyclists & Ambitious cyclist \\
\hline & \multicolumn{2}{|c|}{ Open traditionalists } & $\begin{array}{l}\text { Interested but } \\
\text { Concerned }\end{array}$ & Path-using cyclists & Passionate cyclist \\
\hline \multirow{3}{*}{ NON USERS } & \multicolumn{2}{|c|}{ Gadget lovers } & Enthused and Confident & Fair weather utilitarians & Pragmatic cyclist \\
\hline & \multicolumn{2}{|c|}{ Cautious explorers } & $\begin{array}{l}\text { Interested but } \\
\text { Concerned }\end{array}$ & Leisure cyclists & Functional cyclist \\
\hline & \multicolumn{2}{|c|}{ Opponents } & No way. No how & - & - \\
\hline
\end{tabular}

Source: own elaboration on the basis of literature in the field.

Comparing the characteristics attributed to the first group of Users (people who have used electric bikes), the Gadget Lovers subgroup had the greatest convergence of characteristics with the groups that, according to Geller [71], are most oriented towards cycling-Strong and Fearless, and Enthused and Confident. This is mainly due to their conviction that the bicycle should be used as the main means of transport. For the same reasons, this subgroup also shows similar characteristics to the Dedicated cyclists group designated by Damant-Sirois et al. [75] and the Ambitious cyclists group of Francke et al. [76], due to their high level of commitment to participate in this transport type. As in Geller's typology [71], our subgroup is not the largest one. The subgroup of Open Traditionalists shares traits with Geller's [71] Interested but Concerned because of the low participation of these people in daily cycling. We also find similarities with the Path-using cyclists group of Damant-Sirois et al. [75] because of the wider use of cycling-also for sport and recreation.

In the Non-users group, i.e., people who have not used electric bikes, Gadget Lovers are similar in characteristics to Geller's [71] Enthused and Confident. Parallels can also be seen with Fairweather utilitarians of Damant-Sirois et al. [75] because of the conveniencedependent approach to cycling for transport and the postulated need to encourage cycling. The Cautious Explorers subgroup is characterised by similar characteristics to Geller's [71] Interested but Concerned group. This subgroup also shows similarities to the Leisure cyclists proposed by Damant-Sirois et al. [75], for whom electric bikes primarily have a recreational potential. A similarity to the subgroup of Functional cyclists identified by Francke et al. [76] is also apparent here, as indicated by the lower motivation for frequent cycling among these individuals. The Opponents subgroup, due to its negative attitude towards electric bikes, can be likened to the No Way. No How subgroup in Geller's typology [71]. At the same time, it should be stressed here that not all classifications in the literature included people who do not use bicycles. 
The similarity of the classifications shows that with greater generalisation, regardless of the context (including spatial context), we are dealing with similar groups of opinions about cycling. This is particularly relevant in view of the questions posed about the shape of geographically and culturally determined attitudes. Although it is not possible to unequivocally equate the groups for which typologies have been drawn, it seems to be noteworthy to look for commonalities and similarities. This has its own important implications if we are to better understand on what the respondents representing each group base their opinions. An attempt to compare converging features shown in various studies will allow us to describe those groups better, which in turn will help target cycling measures more precisely. The groups described above represent very different attitudes towards e-bikes. Mobility behaviour also differs between the groups, which to a large extent, determines their attitudes towards transport modes. The strong attachment to the private car is deeply rooted in the transport culture typical of central and eastern European countries, which have entered the phase of egalitarian private cars relatively recently. This means that for part of the population, the car is still an indicator of higher material status. This is certainly a factor hindering the transition to low-carbon mobility, but it does not preclude the changes that are taking place, especially as transport culture can be shaped by an additional element, i.e., the level of environmental awareness. Assuming progress in this area, it can be inferred that susceptibility to responsible choices will increase, also in the area of individual mobility.

However, the above-mentioned geographical context related to cycling culture is not the one that influences the judgements and attitudes to the greatest extent. The psychophysical characteristics of individuals seem to be the ones primarily responsible for the perceived differences. They even seem to influence the ratings more than the experience of using an e-bike or lack thereof. For instance, Opponents and Cautious explorers (Non-users) see more of the negative features of e-bikes, similar to Open traditionalists (Users) (Table 3). Gadget lovers 1 from the Users group perceive e-bikes in a very similar way to Gadget lovers 2 from the Non-users category. The experience of using this mode of transport has not fully convinced Open traditionalists who strongly prefer traditional bicycles, as do the Cautious explorers from the Non-users group. All the groups mentioned recognise, to a varying extent, e-bike applications (Table 4). Gadget lovers 1 and 2 prefer the electric bicycle over the traditional bicycle, whether for commuting, shopping, or leisure trips. Open traditionalists (Users) and Cautious explorers (Non-users) prefer to use a regular bicycle as a means of transport (commuting), and e-bikes when going shopping, to the allotment, or for a trip. Only the Opponents group, unfortunately quite numerous (42.1\% of all respondents), seems to be uninterested in this means of transport altogether-they do not see any positive features, in transport nor recreational applications.

When looking into which of the identified groups could be most inclined to change their mobility behaviour, it seems that according to their declarations, Gadget lovers 1 and 2 are most willing to reduce the use of the car and replace it with an electric bike (Table 5). Of course, this is only a declaration that should be confirmed or refuted in a further study, because what is worrying in the case of the above-mentioned groups is the very frequent use of the car, even for short distances, and the very high rating of the car, both as a means of transport and a recreational tool.

The other groups do not declare a willingness to make such a switch, especially as they primarily see the use for e-bikes in leisure situations in which the use of the car is limited anyway. They associate commuting to work or school, going shopping, or running errands with the car. Perhaps Open traditionalists and Cautious explorers should be further informed of e-bike transport applications. This should be possible since these groups do not exclude the use of e-bikes, and their attitude towards these vehicles is not absolutely negative. The image of the electric bicycle should be improved there, and a shift in emphasis from recreational to transport applications should be made. 
Table 3. Opinions and evaluations on electric bicycles among all types of users and non-users.

\begin{tabular}{|c|c|}
\hline + (Advantages) & - (Disadvantages) \\
\hline \multicolumn{2}{|r|}{ Users } \\
\hline \multicolumn{2}{|c|}{ 1. Gadget lovers $1(3.95 \%)$} \\
\hline $\begin{array}{l}\text { It is trendy }+++ \\
\text { It gives more pleasure from riding it }+++ \\
\text { They prefer to have it }+++ \\
\text { It is more practical }+++ \\
\text { It is more suitable for everyday use }+++ \\
\text { It is more ecological }++\end{array}$ & $\begin{array}{l}\text { It is expensive }--- \\
\text { It is not useful for the elderly }--\end{array}$ \\
\hline \multicolumn{2}{|c|}{ 2. Open traditionalists $(3.95 \%)$} \\
\hline It is especially useful for the elderly ++ & $\begin{array}{l}\text { It is expensive }--- \\
\text { It does not give more pleasure from riding it }--- \\
\text { It is not trendy }--- \\
\text { It is not suitable for everyday use }--- \\
\text { They do not prefer to have it }---\end{array}$ \\
\hline \multicolumn{2}{|r|}{ Non-users } \\
\hline \multicolumn{2}{|c|}{ 3. Opponents (42.1\%) } \\
\hline None & $\begin{array}{l}\text { It is not suitable for everyday use }-- \\
\text { It is not suitable for everyone - } \\
\text { It is less safe - } \\
\text { It is not trendy -- } \\
\text { It is not an indicator of material status - } \\
\text { The fashion for electric bikes is temporary and will } \\
\text { soon pass - }\end{array}$ \\
\hline \multicolumn{2}{|c|}{ 4. Cautious explorers $(28.3 \%)$} \\
\hline It is an indicator of material status + & $\begin{array}{l}\text { It is not suitable for everyone -- } \\
\text { It is less practical - } \\
\text { It is not suitable for everyday use - }\end{array}$ \\
\hline \multicolumn{2}{|c|}{ 5. Gadget lovers $2(21.7 \%)$} \\
\hline $\begin{array}{l}\text { It is suitable for everyone }+++ \\
\text { It is suitable for everyday use }+++ \\
\text { It is more practical }+++ \\
\text { For city dwellers }+++ \\
\text { It is safer }+++ \\
\text { It is trendy }++ \\
\text { They prefer to have it }+++\end{array}$ & None \\
\hline
\end{tabular}

Table 4. The use of the traditional and electric bicycle among all proposed types.

\begin{tabular}{lcc}
\hline & Electric Bicycle & Traditional Bicycle \\
\hline & Users \\
\hline Commuting to work/school & ++ & \\
\hline Shopping & ++ \\
\hline Running errands (e.g., doctor, office, etc.) & + \\
\hline Trip to the allotment & ++ \\
\hline Visiting friends / family & +++ \\
\hline A trip out of town & ++ \\
\hline
\end{tabular}


Table 4. Cont.

\begin{tabular}{|c|c|c|}
\hline & Electric Bicycle & Traditional Bicycle \\
\hline \multicolumn{3}{|c|}{ Users } \\
\hline \multicolumn{3}{|c|}{ 2. Open traditionalists (3.95\%) } \\
\hline Commuting to work/school & & +++ \\
\hline Shopping & & ++ \\
\hline Running errands (e.g., doctor, office, etc.) & & + \\
\hline Trip to the allotment & +++ & \\
\hline Visiting friends/family & +++ & \\
\hline A trip out of town & +++ & \\
\hline \multicolumn{3}{|c|}{ Non-users } \\
\hline \multicolumn{3}{|c|}{ 3. Opponents (42.1\%) } \\
\hline Commuting to work/school & & + \\
\hline Shopping & & ++ \\
\hline Running errands (e.g., doctor, office, etc.) & & ++ \\
\hline Trip to the allotment & & ++ \\
\hline Visiting friends/family & & + \\
\hline A trip out of town & & + \\
\hline \multicolumn{3}{|c|}{ 4. Cautious explorers $(28.3 \%)$} \\
\hline Commuting to work/school & & + \\
\hline Shopping & & + \\
\hline Running errands (e.g., doctor, office, etc.) & & + \\
\hline Trip to the allotment & ++ & \\
\hline Visiting friends/family & + & \\
\hline A trip out of town & ++ & \\
\hline \multicolumn{3}{|c|}{ 5. Gadget lovers $2(21.7 \%)$} \\
\hline Commuting to work/school & +++ & \\
\hline Shopping & +++ & \\
\hline Running errands (e.g., doctor, office, etc.) & +++ & \\
\hline Trip to the allotment & + & \\
\hline Visiting friends/family & ++ & \\
\hline A trip out of town & + & \\
\hline
\end{tabular}

Source: Own elaboration on the basis of the questionnaire survey.

Table 5. Opinions on the car among users and non-users of e-bikes.

\begin{tabular}{|c|c|c|c|c|c|c|}
\hline & \multicolumn{2}{|c|}{ Car } & \multirow{2}{*}{$\begin{array}{l}\text { I Tend to Use My } \\
\text { Car a Lot, Even } \\
\text { for Short } \\
\text { Distances }\end{array}$} & \multirow{2}{*}{$\begin{array}{l}\text { A Bike Is Good for } \\
\text { a Trip, But a Car Is } \\
\text { Better for Everyday } \\
\text { Life }\end{array}$} & \multirow{2}{*}{$\begin{array}{l}\text { I Would Be Happy to } \\
\text { Reduce My Car Use and } \\
\text { Replace It with an } \\
\text { Electric Bike }\end{array}$} & \multirow{2}{*}{$\begin{array}{c}\text { A Car Is an } \\
\text { Indicator of } \\
\text { Higher Material } \\
\text { Status } \\
\end{array}$} \\
\hline & $\begin{array}{l}\text { As a Means } \\
\text { of Transport }\end{array}$ & $\begin{array}{l}\text { As a Tool of } \\
\text { Recreation }\end{array}$ & & & & \\
\hline \multicolumn{7}{|c|}{ Users } \\
\hline Gadget lovers 1 & ++ & ++ & ++ & * & ++ & * \\
\hline $\begin{array}{l}\text { Open } \\
\text { traditionalists }\end{array}$ & --- & --- & -- & -- & -- & + \\
\hline \multicolumn{7}{|c|}{ Non-Users } \\
\hline Opponents & + & - & - & + & - & - \\
\hline $\begin{array}{l}\text { Cautious } \\
\text { explorers }\end{array}$ & -- & + & - & -- & - & - \\
\hline Gadget lovers 2 & + & + & ++ & + & +++ & ++ \\
\hline
\end{tabular}

Explanation: * No relation. Source: own elaboration on the basis of the questionnaire survey. 


\section{Conclusions}

Summarising the obtained results, it should be stressed once more that the comparison of the typology set out in this paper with other existing classifications shows a structure of attitudes towards e-bikes similar to those related to the use of traditional bikes shown, e.g., in the typology of Geller [71]. This is an important observation, indicating once again that the differences between traditional and electric bikes, especially in terms of the advantage of the latter, are still unknown to the public. Similarly, as in the case of traditional bicycle use, there is a smaller, highly committed group participating in e-bicycle transport and a much more numerous group of people unconvinced about this form of transport. If, following the results of the research published to date, e.g., by $[2,3,5,7,8,10]$, we assume that electric bikes could, through their technological advantages over traditional bikes, increase the share of cycling in general; the results obtained in our study indicate that this is possible, but in specific user groups. In terms of our research, these will certainly be the Gadget lovers 1 and 2 (both users and non-users) groups, and to a slightly lesser extent, Cautious explorers and Open traditionalists. Opponents, on the other hand, will require dedicated promotional and educational activities aimed at overcoming their existing attitudes towards e-bikes. However, it seems that these measures will be of great importance, not only for changing the perception of the electric bicycle, or for changing mobility patterns, but predominantly for shaping the whole cycling culture in Poland.

Author Contributions: Conceptualization, J.B., E.G.-K. and M.A.K.; methodology, J.B.; formal analysis, J.B. and E.G.-K.; data curation, J.B., E.G.-K. and M.A.K.; writing-original draft preparation, J.B., E.G.-K. and M.A.K.; writing-review and editing, J.B., E.G.-K. and M.A.K.; visualization, J.B. and E.G.-K. All authors have read and agreed to the published version of the manuscript.

Funding: This research received the external funding from Nicolaus Copernicus University in Torun (Poland).

Institutional Review Board Statement: Not applicable.

Informed Consent Statement: Not applicable.

Data Availability Statement: Not applicable.

Conflicts of Interest: The authors declare no conflict of interest.

\section{References}

1. Bucher, D.; Buffat, R.; Froemelt, A.; Raubal, M. Energy and greenhouse gas emission reduction potentials resulting from different commuter electric bicycle adoption scenarios in Switzerland. Renew. Sustain. Energy Rev. 2019, 114, 109298. [CrossRef]

2. Fishman, E.; Cherry, C. E-bikes in the Mainstream: Reviewing a Decade of Research. Transp. Rev. 2016, 36, 72-91. [CrossRef]

3. Rérat, P. The rise of the e-bike: Towards an extension of the practice of cycling? Mobilities 2021, in press. [CrossRef]

4. Behrendt, F. Why cycling matters for electric mobility: Towards diverse, active and sustainable e-mobilities. Mobilities 2018, 13, 64-80. [CrossRef]

5. Marincek, D.; Rérat, P. From conventional to electrically-assisted cycling. A biographical approach to the adoption of the e-bike. Int. J. Sustain. Transp. 2020, 15, 768-777. [CrossRef]

6. Dill, J.; Rose, G. Electric Bikes and Transportation Policy: Insights from Early Adopters. Transp. Res. Rec. 2012, 2314, 1-6. [CrossRef]

7. Rose, G. E-bikes and urban transportation: Emerging issues and unresolved questions. Transportation 2012, 39, 81-96. [CrossRef]

8. Ling, Z.; Cherry, C.R.; MacArthur, J.H.; Weinert, J.X. Differences of Cycling Experiences and Perceptions between E-Bike and Bicycle Users in the United States. Sustainability 2017, 9, 1662. [CrossRef]

9. Bieliński, T.; Kwapisz, A.; Ważna, A. Electric bike-sharing services mode substitution for driving, public transit and cycling. Transp. Res. Part D-Transp. Environ. 2021, 96, 102883. [CrossRef]

10. Kwiatkowski, M.A.; Grzelak-Kostulska, E.; Biegańska, J. Could it be a bike for everyone? The electric bicycle in Poland. Energies 2021, 14, 4878. [CrossRef]

11. Johnson, M.; Rose, G. Extending life on the bike: Electric bike use by older Australians. J. Transp. Health 2015, 2, $276-283$. [CrossRef]

12. Van Cauwenberg, J.; De Bourdeaudhuij, I.; Clarys, P.; De Geus, B. E-bikes among older adults: Benefits: Disadvantages, usage and crash characteristics. Transportation 2019, 46, 2151-2172. [CrossRef] 
13. Mayer, A. Motivations and barriers to electric bike use in the U.S.: Views from online forum participants. Int. J. Urban Sustain. Dev. 2020, 12, 160-168. [CrossRef]

14. Hiselius, L.W.; Svensson, A. E-bike use in Sweden- $\mathrm{CO}_{2}$ effects due to modal change and municipal promotion strategies. J. Clean. Prod. 2017, 141, 818-824. [CrossRef]

15. Salmeron-Manzano, E.; Manzano-Agugliaro, F. The Electric Bicycle: Worldwide Research Trends. Energies 2018, 11, 1894. [CrossRef]

16. Gojanovic, B.; Welker, J.; Iglesias, K.; Daucourt, C.; Gremion, G. Electric bicycles as a New Active Transportation Modality to Promote Health. Med. Sci. Sports Exerc. 2011, 43, 2204-2210. [CrossRef]

17. Bourne, J.E.; Sauchelli, S.; Perry, R.; Page, A.; Leary, S.; England, C.; Cooper, A.R. Health benefits of electrically-assisted cycling: A systematic review. Int. J. Behav. Nutr. Phys. Act. 2018, 15, 116. [CrossRef]

18. Fyhri, A.; Heinen, E.; Fearnley, N.; Sundfor, H.B. A push to cycling-Exploring the e-bike's role in overcoming barriers to bicycle use with a survey and an intervention study. Int. J. Sustain. Transp. 2017, 11, 681-695. [CrossRef]

19. Andersson, A.S.F.K.A.; Adell, E.; Hiselius, L.W. What is the substitution effect of e-bikes? A randomised controlled trial. Transp Res. Part D-Transp. Environ. 2021, 90, 102648. [CrossRef]

20. Haustein, S.; Moller, M. Age and attitude: Changes in cycling patterns of different e-bike user segments. Int. J. Sustain. Transp. 2016, 10, 836-846. [CrossRef]

21. Kwiatkowski, M.A.; Szymańska, D. Cycling policy in strategic documents of Polish cities. Environ. Dev. Sustain. 2021, 23, 10357-10377. [CrossRef]

22. Reinhardt, R.; Gurtner, S. Differences between early adopters of disruptive and sustaining innovations. J. Bus. Res. 2015, 68, 137-145. [CrossRef]

23. Seebauer, S. Why early adopters engage in interpersonal diffusion of technological innovations: An empirical study on electric bicycles and electric scooters. Transp. Res. Part A 2015, 78, 146-160. [CrossRef]

24. Wolf, A.; Seebauer, S. Technology adoption of electric bicycles: A survey among early adopters. Transp. Res. Part A-Policy Pract. 2014, 69, 196-211. [CrossRef]

25. Wejnert, B. Integrating models of diffusion of innovations. A conceptual framework. Ann. Rev. Soc. 2002, 28, 297-326. [CrossRef]

26. Zhang, T.; Gensler, S.; Garcia, R. A study of the diffusion of alternative fuel vehicles. An agent-based modeling approach. J. Prod. Innov. Manag. 2011, 28, 152-168. [CrossRef]

27. Axsen, J.; Kurani, K.S. Interpersonal influence within car buyers' social networks. Applying five perspectives to plug-in hybrid vehicle drivers. Environ. Plan. A 2012, 44, 1047-1065. [CrossRef]

28. Gatersleben, B.; Appleton, K.M. Contemplating cycling to work: Attitudes and perceptions in different stages of change. Transp. Res. Part A Policy Pract. 2007, 41, 302-312. [CrossRef]

29. Gao, Y.; Shahab, S.; Ahmadpoor, N. Morphology of Urban Villages in China: A Case Study of Dayuan Village in Guangzhou. Urban Sci. 2020, 4, 23. [CrossRef]

30. Boeing, G. The Morphology and Circuity of Walkable and Drivable Street Networks. In The Mathematics of Urban Morphology; Birkhäuser: Cham, Switzerland, 2019; pp. 271-287. [CrossRef]

31. Scorza, F.; Fortunato, G. Cyclable Cities: Building Feasible Scenario through Urban Space Morphology Assessment. J. Urban Plan. Dev. 2021, 147, 05021039. [CrossRef]

32. Bartels, J.; Reinders, M.J. Consumer innovativeness and its correlates: A propositional inventory for future research. J. Bus. Res. 2011, 64, 601-609. [CrossRef]

33. Goldsmith, R.E.; Hofacker, C.F. Measuring consumer innovativeness. J. Acad. Mark. Sci. 1991, 19, 209-221. [CrossRef]

34. Hunecke, M.; Haustein, S.; Grischkat, S.; Böhler, S. Psychological, sociodemographic, and infrastructural factors as determinants of ecological impact caused by mobility behavior. J. Environ. Psychol. 2007, 27, 277-292. [CrossRef]

35. Moore, G.A. Crossing the Chasm; Harper Collins Publishers: New York, NY, USA, 2014.

36. Dattée, B.; Weil, H.B. Dynamics of social factors in technological substitutions. Technol. Forecast. Soc. Chang. 2007, 74, 579-607. [CrossRef]

37. Rogers, E.M. Diffusion of Innovations, 5th ed.; Free Press: New York, NY, USA, 2003.

38. Dedehayir, O.; Ortt, R.J.; Riverola, C.; Miralles, F. Innovators and Early Adopters in the Diffusion of Innovations: A Literature Review. Int. J. Innov. Manag. 2017, 21, 1740010. [CrossRef]

39. Delre, S.; Jager, W.; Bijmolt, T.; Janssen, M. Will it spread or not? The effects of social influences and network topology on innovation diffusion. J. Prod. Innov. Manag. 2010, 27, 267-282. [CrossRef]

40. Bamberg, S.; Hunecke, M.; Blöbaum, A. Social context, personal norms and the use of public transportation: Two field studies. J. Environ. Psychol. 2007, 27, 190-203. [CrossRef]

41. Dijk, M.; Kemp, R.; Valkering, P. Incorporating social context and co-evolution in an innovation diffusion model-With an application to cleaner vehicles. J. Evol. Econ. 2011, 23, 295-329. [CrossRef]

42. Egbue, O.; Long, S. Barriers to widespread adoption of electric vehicles. An analysis of consumer attitudes and perceptions. Energy Policy 2012, 48, 717-729. [CrossRef]

43. Oliver, J.D.; Rosen, D.E. Applying the environmental propensity framework: A segmented approach to hybrid electric vehicle marketing strategies. J. Mark. Theory Pract. 2010, 18, 377-393. [CrossRef] 
44. Edge, S.; Dean, J.; Cuomo, M.; Keshav, S. Exploring e-bikes as a mode of sustainable transport: A temporal qualitative study of the perspectives of a sample of novice riders in a Canadian City. Can. Geogr.-Geogr. Can. 2018, 62, 384-397. [CrossRef]

45. Gu, T.Q.; Kim, I.; Currie, G. The two-wheeled renaissance in China-an empirical review of bicycle, E-bike, and motorbike development. Int. J. Sustain. Transp. 2020, 15, 239-258. [CrossRef]

46. Zuev, D. Urban Mobility in Modern China: The Growth of the E-Bike; Springer: Berlin/Heidelberg, Germany, 2018.

47. Zuev, D.; Tyfield, D.; Urry, J. Where is the politics? E-bike mobility in urban China and civilizational government. Environ. Innov. Soc. Transit. 2019, 30, 19-32. [CrossRef]

48. Ling, Z.; Cherry, C.R.; Yang, H.; Jones, L.R. From e-bike to car: A study on factors influencing motorization of e-bike users across China. Transp. Res. Part D Transp. Environ. 2015, 41, 50-63. [CrossRef]

49. Ogrodzka, D. Koło Wciśnięte w Szczelinę. Mała Kultura Współczesna. 2011. Available online: Malakulturawspolczesna.org/2011 /03/14/dorota-kolo-wcisniete-W-szczeline/ (accessed on 20 June 2021).

50. Popovich, N.; Gordon, E.; Shao, Z.; Xing, Y.; Wang, Y.; Handy, S. Experiences of electric bicycle users in the Sacramento, California area. Travel Behav. Soc. 2014, 1, 37-44. [CrossRef]

51. Leger, S.J.; Dean, J.L.; Edge, S.; Casello, J.M. "If I had a regular bicycle, I wouldn't be out riding anymore": Perspectives on the potential of e-bikes to support active living and independent mobility among older adults in Waterloo, Canada. Transp. Res. Part A-Policy Pract. 2019, 123, 240-254. [CrossRef]

52. Van Lierop, D.; Soemers, J.; Hoeke, L.; Liu, G.; Chen, Z.; Ettema, D.; Kruijf, J. Wayfinding for cycle highways: Assessing e-bike users' experiences with wayfinding along a cycle highway in the Netherlands. J. Transp. Geogr. 2020, 88, 102827. [CrossRef]

53. Barbu, A.; Isaic-Maniu, A. Data collection in romanian market research: A comparison between prices of PAPI, CATI and CAWI. Manag. Mark. 2011, 6, 349-364. Available online: https://www.proquest.com/scholarly-journals / data-collection-romanianmarket-research/docview/899217175/se-2?accountid=7976 (accessed on 20 August 2021).

54. Kagerbauer, M.; Manz, W.; Zumkeller, D. Analysis of PAPI, CATI, and CAWI Methods for a Multiday Household Travel Survey. In Transport Survey Methods; Zmud, J., Lee-Gosselin, M., Munizaga, M., Carrasco, J.A., Eds.; Emerald Group Publishing Limited: Bingley, UK, 2013; pp. 289-304. [CrossRef]

55. D'Ancona, M.A.C. Measuring multiple discrimination through a survey-based methodology. Soc. Sci. Res. 2017, 67, 239-251. [CrossRef]

56. Instytut Badań Pollster. Available online: https:// pollster.pl/cawi (accessed on 22 June 2021).

57. Babbie, E. The Basics of Social Research; Cengage Learning: Stamford, CT, USA, 2015.

58. Pham, D.T.; Dimov, S.S.; Nguyen, C.D. Selection of K in K-means clustering. Proc. Inst. Mech. Eng. Part C J. Mech. Eng. Sci. 2005, 219, 103-119. [CrossRef]

59. Likas, A.; Vlassis, N.; Verbeek, J.J. The global k-means clustering algorithm. Pattern Recognit. 2003, 36, 451-461. [CrossRef]

60. Na, S.; Xumin, L.; Yong, G. Research on k-means Clustering Algorithm: An Improved k-means Clustering Algorithm. In Proceedings of the 2010 Third International Symposium on Intelligent Information Technology and Security Informatics, Jian, China, 2-4 April 2010; pp. 63-67. [CrossRef]

61. Vattani, A. K-means Requires Exponentially Many Iterations Even in the Plane. Discret. Comput. Geom. 2011, 45, 596-616. [CrossRef]

62. Steinley, D. Standardizing Variables in K-means Clustering. In Classification, Clustering, and Data Mining Applications. Studies in Classification, Data Analysis, and Knowledge Organisation; Banks, D., McMorris, F.R., Arabie, P., Gaul, W., Eds.; Springer: Berlin/Heidelberg, Germany, 2004. [CrossRef]

63. Mohamad, I.B.; Usman, D. Standardization and Its Effects on K-Means Clustering Algorithm. Res. J. Appl. Sci. Eng. Technol. 2013, 6, 3299-3303. [CrossRef]

64. Foxall, G.R. Behavior analysis and consumer psychology. J. Econ. Psychol. 1994, 15, 5-91. [CrossRef]

65. Turrentine, T.; Garas, D.; Lentz, A.; Woodjack, J. The UC Davis MINI E Consumer Study; Plug-in Hybrid \& Electric Vehicle Research Center, Institute of Transportation Studies, University of California; Davis: Davis, CA, USA, 2011.

66. Moser, C.; Blumer, Y.; Hille, S.L. E-bike trials' potential to promote sustained changes in car owners mobility habits. Environ. Res. Lett. 2018, 13, 044025. [CrossRef]

67. Kaplan, S.; Wrzesinska, D.K.; Prato, C.G. The role of human needs in the intention to use conventional and electric bicycle sharing in a driving-oriented country. Transp. Policy 2018, 71, 138-146. [CrossRef]

68. Felix, R.; Moura, F.; Clifton, K.J. Typologies of Urban Cyclists Review of Market Segmentation Methods for Planning Practice. Transp. Res. Rec. 2017, 2662, 125-133. [CrossRef]

69. Goel, R.; Goodman, A.; Aldred, R.; Nakamura, R.; Tatah, L.; Garcia, L.M.T.; Diomedi-Zapata, B.; de Sa, T.H.; Tiwari, G.; de Nazelle, A.; et al. Cycling behaviour in 17 countries across 6 continents: Levels of cycling, who cycles, for what purpose, and how far? Transp. Rev. 2021, 1-24, ahead-of-print. [CrossRef]

70. Tengattini, S.; Bigazzi, A.; Rupi, F. Appearance and behaviour: Are cyclist physical attributes reflective of their preferences and habits? Travel Behav. Soc. 2018, 13, 36-43. [CrossRef]

71. Geller, R. Four Types of Cyclists; Portland Bureau of Transportation: Portland, OR, USA, 2006. Available online: https:// portlandoregon.gov/transportation/article/264746 (accessed on 10 December 2021).

72. Dill, J.; McNeil, N. Four Types of Cyclists? Examination of Typology for Better Understanding of Bicycling Behavior and Potential. Transp. Res. Rec. 2013, 2387, 129-138. [CrossRef] 
73. Dill, J.; McNeil, N. Revisiting the Four Types of Cyclists Findings from a National Survey. Transp. Res. Rec. 2016, $2587,90-99$. [CrossRef]

74. Cabral, L.; Kim, A.M. An empirical reappraisal of the four types of cyclists. Transp. Res. Part A Policy Pract. 2020, 137, 206-221. [CrossRef]

75. Damant-Sirois, G.; Grimsrud, M.; El-Geneidy, A.M. What's your type: A multidimensional cyclist typology. Transportation 2014 41, 1153-1169. [CrossRef]

76. Francke, A.; Anke, J.; Lissner, S.; Schaefer, L.M.; Becker, T.; Petzoldt, T. Are you an ambitious cyclist? Results of the cyclist profile questionnaire in Germany. Traffic Inj. Prev. 2019, 20, S10-S15. [CrossRef]

77. Vogel, M.; Hamon, R.; Lozenguez, G.; Merchez, L.; Abry, P.; Barnier, J.; Borgnat, P.; Flandrin, P.; Mallon, I.; Robardet, C. From bicycle sharing system movements to users: A typology of Velo'v cyclists in Lyon based on large-scale behavioural dataset. J. Transp. Geogr. 2014, 41, 280-291. [CrossRef]

78. Mitra, R.; Schofield, J. Biking the First Mile: Exploring a Cyclist Typology and Potential for Cycling to Transit Stations by Suburban Commuters. Transp. Res. Rec. 2019, 2673, 951-962. [CrossRef] 